\title{
O Servidor Público no Mundo do Trabalho do Século XXI
}

\author{
The Public Servant In The Labor World \\ Of The 21St Century
}

El Empleado Público En El Mundo

Del Trabajo Del Siglo XXI
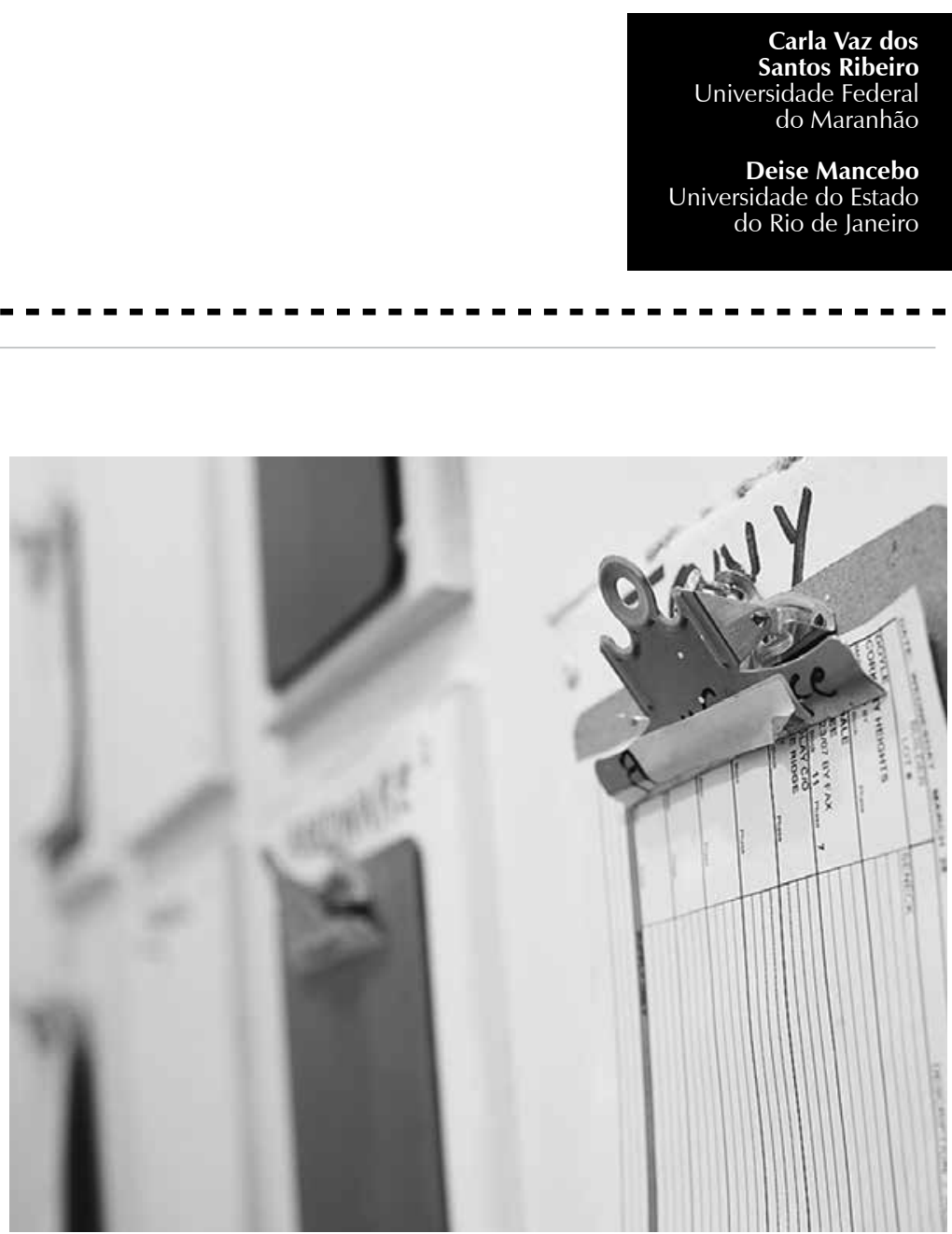
Resumo: O texto aborda as repercussões do discurso depreciativo da sociedade dirigido ao servidor público - em muito intensificado pelas mutações no mundo do trabalho na virada do século XX para o XXI - na subjetividade dessa categoria e investiga como esses trabalhadores convivem com a utilização corrente de estereótipos negativos que desqualificam e desvalorizam a sua atividade laboral. O texto discute ainda como a falta de reconhecimento e de valorização interfere no sentido atribuído pelos servidores públicos à sua vida profissional. O texto analisa também as transformações ocorridas no setor público nas últimas décadas, em especial, as mudanças provocadas a partir da implementação da Reforma do Estado, de 1995, no Brasil, constata que a crise do Estado-providência influencia de maneira decisiva as políticas, as estruturas e a cultura das organizações estatais e identifica um novo cenário que gera significativos impactos na produção da subjetividade da categoria; por fim, questiona se ainda há espaço para o servidor público no mundo do trabalho contemporâneo.

Palavras-chave: Administração pública. Trabalho. Desvalorização. Subjetividade.

Abstract: The present work discusses the repercution of the increasing depreciative speech towards the civil servant - greatly influenced by changes in the labor world at the turning of the century - in the subjectivity in this category. It also discusses how these workers deal with the frequently negative stereotypes that diminish and deppreciate their labor and explains how the lack of recognition and appreciation interferes in the sense given by civil servants to their professional life. An analysis of the changes in the public sector management over the last decade is also provided, with special emphasis on the consequences of the implementation of the 1995 Brazilian State Reform. The work concludes that the current global Welfare State crisis, translated as the pressure for a lean government body affects significantly the environment of Brazilian politics and the organization and ethos of its public institutions. The work identifies a new scenario that generates significant impacts on the production of subjectivity in the category. Finally, it questions whether there is place for the public servant in the world of contemporary work.

Keywords: Public administration. Work. Devaluation. Subjectivity.

Resumen: El texto aborda las repercusiones del discurso despectivo de la sociedad dirigido al empleado público - en mucho intensificado por las mutaciones en el mundo del trabajo en el cambio del siglo XX para el XXI - en la subjetividad de esa categoría e investiga como esos trabajadores conviven con la utilización corriente de estereotipos negativos que descalifican y desvalorizan su actividad laboral. El texto discute también como la falta de reconocimiento y de valorización interfiere en el sentido atribuido por los servidores públicos a su vida profesional. El texto analiza también las transformaciones ocurridas en el sector público en las últimas décadas, en especial, los cambios provocados desde la implementación de la Reforma del Estado, de 1995, en Brasil, constata que la crisis del Estado-providencia influencia de manera decisiva las políticas, las estructuras y la cultura de las organizaciones estatales e identifica un nuevo escenario que genera significativos impactos en la producción de la subjetividad de la categoría; por fin, cuestiona si aún hay espacio para el servidor público en el mundo del trabajo contemporáneo.

Palabras clave: Administración pública. Trabajo. Desvalorización. Subjetividad.

\section{Situando a reflexão}

O presente ensaio teórico discute os impactos do discurso depreciativo da sociedade e dirigido aos servidores públicos na constituição da subjetividade dessa categoria, busca analisar as transformações ocorridas no serviço público nas últimas décadas, em especial, as mudanças provocadas a partir da implementação da Reforma do Estado de 1995 no Brasil e, por fim, levanta questionamentos sobre o espaço, porventura existente, de reconhecimento e de valorização do servidor público no mundo do trabalho do século XXI.
Cabe esclarecer que o sentido dado ao termo servidor público está restrito aos servidores ocupantes de cargo público. Essa diferenciação se torna necessária, pois o conceito de servidor público compreende, segundo Di Pietro (2010), três grupos distintos: o primeiro, dos servidores estatutários, titulares de cargos públicos, submetidos em lei a regulamentos estabelecidos pelas unidades da Federação; o segundo, dos empregados públicos subordinados às normas da CLT e ocupantes de emprego público, e o último grupo, dos servidores temporários contratados para exercer funções por prazo determinado. 
Faz-se essa distinção por serem consideráveis as diferenças existentes entre essas três categorias no que se refere aos aspectos de estabilidade, processo seletivo, previdência social, remuneração e oportunidades de carreira.

A discussão está pautada nas seguintes premissas: acumulação flexível, mudancas no mundo do trabalho e subjetividade do servidor público.

\section{Considerações sobre as repercussões das transformações no mundo do trabalho no serviço público}

Nas últimas décadas, a classe-que-vive-dotrabalho tem vivenciado um quadro crítico de grande complexidade frente à crise estrutural do capital, marcada por um contínuo depressivo. Conforme Antunes,

\begin{abstract}
No meio do furacão da crise que agora atinge o coração do sistema capitalista, vemos a erosão do trabalho relativamente contratado e regulamentado herdeiro da era taylorista e fordista, ... que está sendo substituído pelas diversas formas de 'empreendedorismo', 'cooperativismo', 'trabalho voluntário', 'trabalho atípico', formas que oscilam entre a superexploração e a própria auto-exploração do trabalho, sempre caminhando em direção a uma precarização estrutural da força de trabalho em escala global (2009, p.13)
\end{abstract}

Essa crise (ou conjunto de crises) tem gerado, entre tantas consequências, profundas mudanças no interior do mundo do trabalho. Ocorrem "mutações intensas, econômicas, sociais, políticas, ideológicas, com fortes repercussões no ideário, na subjetividade e nos valores constitutivos da classe-que-vivedo-trabalho" (Antunes, 1999, p.35).

Na tentativa de superá-la, mas mantendo intocado o modo de produção, experimentam- se novas formas de organização industrial e de relacionamento entre o capital e o trabalho. Exige-se um novo perfil de trabalhador: diferente, mais qualificado, participativo e polivalente. As organizações precisam analisar os seus processos, adaptar e reformular todo o seu planejamento e o modo de conduzir os trabalhos, objetivando reduzir custos e aumentar a competitividade. É nesse contexto que se consolida o modelo de produção japonês, também conhecido como toyotismo, que possibilita uma produção vinculada à demanda, mais individualizada, diversificada, suficientemente flexível para atender às novas necessidades mercadológicas e acompanhar as constantes mudanças vivenciadas no mundo capitalista.

Harvey comenta que essa reestruturação radical se caracteriza por uma passagem para um regime de acumulação inteiramente novo dentro do capitalismo, com significativas inovações nos setores de produção, no fornecimento dos serviços, no comércio e nas tecnologias utilizadas. "Acumulação flexível" é a expressão que o autor emprega para designar "o confronto direto com a rigidez do fordismo (pois esse modelo de produção) se apóia na flexibilidade dos processos de trabalho, dos mercados de trabalho, dos produtos e padrões de consumo" (Harvey, 1993, p.140).

Muitas empresas realizam um verdadeiro desmonte em sua organização, dividindose em pequenos grupos por diferentes partes do mundo. Elas são conhecidas como transnacionais, e caracterizam-se pela utilização de vários tipos de contrato de trabalho e pela dispersão dos processos de produção em várias nações. Um certo produto pode, dentro desse sistema, ter seus componentes produzidos em diversas regiões do mundo e ser montado em alguma outra localidade específica. Essas empresas diferem das multinacionais por 
não seguirem um modelo de administração de uma matriz. Em cada local em que ingressam, vão modelando-se, buscando usufruir o máximo das vantagens existentes. Em algumas circunstâncias, terceirizam, em outras subcontratam; por vezes, limitam-se a um acordo com fornecedores. Na escolha do local de instalação de uma organização, novos fatores são determinantes, tais como: menor politização dos trabalhadores, mão de obra mais barata, isenção de impostos, menos imposições em relação à preservação do meio ambiente, enfim, vários aspectos relacionados à diminuição de custos e ao consequente aumento dos lucros.

As organizações encontram-se mais enxutas, flexíveis e descentralizadas. Em oposição à fábrica gorda do modelo taylorista/fordista, nasce a fábrica magra, caracterizada por uma estrutura flexível e transparente capaz de absorver, com um número reduzido de pessoal, as flutuações quantitativas e qualitativas da demanda.

Nas entrelinhas se desenha aqui aquilo
que seríamos tentados a designar como
a 'fábrica mínima', a fábrica reduzida às
suas funções, equipamentos e efetivos
estritamente necessários para satisfazer
a demanda diária ou semanal. Observe-
se também que, no espírito de Ohno, a
fábrica mínima é primeiramente e antes de
tudo a fábrica do pessoal mínimo (Coriat,
1994, p.33)

Assim, a lógica do mercado de trabalho atual se caracteriza por "reduzir o número de trabalhadores 'centrais' e empregar cada vez mais uma força de trabalho que entra facilmente e é demitida sem custos quando as coisas ficam ruins" (Harvey, 1993, p.144).

Essas mutações no processo produtivo promovem, portanto, uma série de impactos decisivos, como: desregulamentação dos direitos do trabalho, terceirização e precarização da classe trabalhadora, níveis relativamente altos de desemprego estrutural e enfraquecimento do sindicalismo de classe.

Todo esse receituário das mudanças no mundo do trabalho, acompanhado de perto por um discurso que advoga a necessidade de enxugamento também das funções até então atribuídas aos Estados, atingem, profundamente, o serviço público. Na realidade, ocorrem, em muitas situações e países, uma desmontagem do setor produtivo estatal, ondas de privatização que retiram setores, antes considerados estratégicos, da mão dos Estados nacionais.

O poder das corporações transnacionais ultrapassa as fronteiras das nações e coloca em xeque com frequência a soberania dos Estados. É flagrante a "perda da capacidade dos Estados nacionais em regularem a economia, frente ao poderio inusitado do sistema financeiro internacional e do grande capital produtivo oligopolista globalizados, bem como pela ascensão da ideologia neoliberal, em detrimento do keynesianismo "(Mancebo, 2007, pp.74-75).

O serviço público é considerado ineficiente e muito oneroso, e, em função disso, precisa enfrentar todo um processo de reestruturação. A lógica da fábrica magra se estende aos órgãos públicos, influenciando de maneira decisiva as políticas, as estruturas e a cultura das organizações estatais.

A crise do Estado-providência, onde ele ocorreu, dá lugar a um movimento reformista que tem como proposta básica a substituição do modelo de gestão burocrático pelo gerencial. O Estado passa a conviver com a gradativa incorporação da lógica e dos mecanismos que regem o mundo das empresas privadas com o objetivo de propiciar agilidade, eficiência e qualidade aos serviços. 
O uso das

palavras gestão, management, gerir e manager é tão comum que chegamos ao ponto de as pessoas não expressarem mais suas emoções, e sim, gerenciá-las (Chanlat, 2002).
O movimento em questão, conhecido como gerencialismo, disseminou-se em vários países do mundo e guarda uma estreita relação nas suas ações e valores com a reestruturação produtiva do pós-fordismo (Paula, 2005a).

Segundo Chanlat (2002), o gerencialismo descreve, explica e interpreta o mundo a partir das categorias da gestão privada, lançando mão de noções e de princípios administrativos tais como: eficácia, produtividade, performance, competência, empreendedorismo, qualidade total, cliente, produto, marketing, desempenho, excelência e reengenharia.

Essas noções e princípios do gerencialismo "estão cada vez mais entrelaçados no tecido social, pois não é mais possível ignorar que as organizações empresariais exercem uma grande influência na sociedade" (Paula, 2005a, p.57), de modo que a cultura do management invade os mais diversos tipos de organizações, tais como escolas, hospitais, universidades, administrações públicas, organizações sem fins lucrativos e até igrejas. A presença crescente do pensamento gerencial transformou a figura do gerente em uma das figuras centrais da sociedade contemporânea. O uso das palavras gestão, management, gerir e manager é tão comum que chegamos ao ponto de as pessoas não expressarem mais suas emoções, e sim, gerenciá-las (Chanlat, 2002).

No Brasil, esse movimento ganhou força no serviço público nos anos 90 do século XX, mais especificamente com a indicação de Bresser-Pereira para assumir o Ministério da Administração e Reforma do Estado (MARE), no governo de Fernando Henrique Cardoso. Em janeiro de 1995, o ex-ministro apresentou o Plano Diretor da Reforma do Estado, dando início ao processo de implantação da administração pública gerencial.
A reforma em questão, também conhecida como nova administração pública, objetivava efetivar a transição do modelo burocrático para o gerencial. Segundo Bresser-Pereira e Spink (2006), algumas características definem esse novo modelo: descentralização administrativa, pressuposto de confiança limitada nos gestores públicos e não de desconfiança total, incentivo à criatividade e à inovação, orientação para resultados com controle a posteriori, em vez de controle rígido e burocrático dos processos administrativos, orientação para servir ao público, considerando o indivíduo em termos econômicos, como consumidor (ou usuário) e, em termos políticos, como cidadão.

O princípio básico era tornar a administração pública brasileira mais flexível, eficiente, com serviços de melhor qualidade e custos reduzidos, em contraposição à administração burocrática, caracterizada como rígida, hierarquizada, autocentrada, onerosa, pesada, ineficiente e prestadora de maus serviços. Para tal, foi proposta a subdivisão do aparelho do Estado em quatro setores, delimitando uma nova área de atuação do Governo:

a) núcleo estratégico do Estado - constituído pelo Legislativo, Judiciário, Presidência e cúpula dos Ministérios. Também integram essa categoria os Governadores, seus secretários e a alta administração pública estadual;

b) atividades exclusivas do Estado englobam as atividades que garantem o cumprimento das leis e das políticas públicas, e compreendem as Forças Armadas, a polícia, as agências de fiscalização, de financiamento, de regulamentação, de controle social e de seguridade social;

c) serviços não exclusivos do Estado abrangem os serviços de educação, saúde, cultura e pesquisa científica. Esses serviços 
podem ficar sob o controle do Estado, podem ser privatizados ou serem subsidiados pelo Estado, mas são controlados pela sociedade, isto é, passam a ser convertidos em organizações públicas não estatais;

d) setor de produção de bens e serviços para o mercado - constituído pelas empresas estatais (Bresser-Pereira \& Spink, 2006).

As instituições prestadoras de serviços não exclusivos do Estado, segundo Bresser-Pereira e Spink, deveriam ser transformadas "em um tipo especial de entidade não-estatal - as organizações sociais..., ou seja, em entidades que celebrem um contrato de gestão com o Poder Executivo e contem com autorização do Parlamento para participar do orçamento próprio" (2006, p.263). Essas entidades assumiriam a forma de fundações públicas de direito privado criadas por pessoas físicas, possibilitando, desse modo, maior autonomia administrativa e financeira. Os servidores provenientes das instituições público-estatais constituiriam, assim, uma categoria em extinção, e os novos empregados seriam contratados pelo regime da Consolidação das Leis do Trabalho (CLT).

Nesse sentido, o Estado precisaria atuar como um regulador e transferidor de recursos, e não como um executor. Defendia-se, assim, a concepção de que a forma de constituição dominante do moderno Estado do século XXI deveria ser de organizações públicas não estatais, portanto, somente as organizações compreendidas no núcleo estratégico e nas atividades exclusivas permaneceriam como estatais.

De acordo com Bresser-Pereira e Spink, no capitalismo contemporâneo, existem três formas de propriedade relevantes: “a) a propriedade privada, voltada para a realização do lucro (empresa) ou de consumo privado (famílias), b) a propriedade públicoestatal e c) a propriedade pública não estatal" (p.261). Buscando melhor delimitação dos tipos de propriedades, o autor aponta o espaço público como algo mais amplo que o estatal. Afirma que público é o que se dedica ao interesse geral e não visa ao lucro, e estatal é o que faz parte do aparelho do Estado e explica que o sentido de público está presente tanto nas instituições público-estatais como também nas instituições de direito privado voltadas para o interesse público, que se encaixam na condição de públicas não estatais, permitindo assim um controle misto tanto do mercado quanto do Governo.

Identifica-se, por conseguinte, nesse período, o lançamento das bases para a implementação do gerencialismo no serviço público brasileiro, com vistas ao alcance de um Estado mínimo e enxuto. Contudo, a substituição do modelo de administração burocrática pelo gerencial como solução para os problemas de eficiência e eficácia das organizações públicas é discutida por diversos teóricos que apontam incompatibilidades entre a lógica gerencialista e o interesse público (Azevedo \& Loureiro, 2003; Chanlat, 2002; Paula, 2005a, 2005b; Siqueira \& Mendes, 2009).

Chanlat alerta que as práticas de gestão oriundas do setor empresarial, calcadas na lógica dos negócios e em bases cada vez mais mercantis, tendem a colocar em risco a imparcialidade, o tratamento igualitário e a ética do interesse geral, princípios esses fundamentais em uma ação de utilidade pública. O autor afirma ainda que "historicamente, não há desenvolvimento equilibrado sem uma burocracia competente, íntegra, independente e dedicada à causa do bem comum" (2002, p.7).

Nessa mesma direção, Azevedo e Loureiro complementam a ideia de que substituir 
o modelo burocrático - visto como excessivamente formalista, autocentrado e ineficiente - pelo modelo gerencial como solução para os problemas da administração pública é parcialmente verdadeira. Para os autores, o modelo burocrático é o mais compatível com uma ordem republicana e democrática, por conter os princípios fundamentais do Estado de Direito, tais como: legalidade, impessoalidade, regras formais e universais; entretanto, ressaltam a necessidade de flexibilização e de aperfeiçoamento dos mecanismos de controle, somadas à adoção de formas mais adequadas, ágeis e criativas para realizar os princípios da administração do Estado, como condição para sua manutenção nos governos democráticos contemporâneos.

Siqueira e Mendes alertam sobre os riscos da importação de tecnologias gerenciais do setor privado sem a devida adequação à filosofia de trabalho e à cultura organizacional do serviço público. Os autores sinalizam, ainda, a necessidade de se "conhecer um pouco mais do que há escamoteado nos modelos importados do setor privado, e principalmente as dimensões do controle, especialmente do nível ideológico" (2009, p. 245).

A incompatibilidade da lógica de funcionamento gerencial com o interesse público também é abordada por Paula (2005b), quando questiona a viabilidade da transferência do conhecimento gerado no setor privado para o setor público. A autora argumenta que o gerencialismo tende a ficar restrito aos aspectos técnicos da administração, sem conseguir integrar esses elementos à complexidade e os desafios da dinâmica política que é inerente à gestão pública, diferentemente da empresa privada, que atende a interesses particulares e individualizados, a organização pública tem por finalidade atender às mais variadas demandas da coletividade, destinando seus objetivos e ações ao cliente-cidadão.

No que se refere à autonomia, identificam-se também percalços na transposição das práticas advindas do setor privado. A aplicabilidade do gerencialismo em organizações privadas é bem distinta da sua aplicabilidade em organizações públicas estatais. Enquanto o gestor de uma empresa privada pode redefinir metas, intervir na estrutura e alterar o seu quadro de pessoal, o gestor público precisa desenvolver habilidades para atuar frente a estruturas organizacionais limitadas por toda uma legislação que rege os órgãos públicos, mantidas com recursos incertos e engessados em rubricas, compostas por um quadro de funcionários controlado pelo Governo, além da constante pressão política. Ele só pode fazer o que a lei prescreve, além de não poder intervir diretamente na missão, na vocação e nos valores da sua organização.

Outras análises se fazem necessárias para uma crítica mais aprofundada no que diz respeito ao alcance e às limitações do modelo gerencial. Todavia, pode-se deduzir que a eficiência do gerencialismo está cercada de limites, em especial, quando se trata do setor público. Sabe-se que as organizações públicas são atravessadas por modelos mistos, por conflitos e desencontros de modelos teoricamente distintos, mas intensamente imbricados na prática. O cotidiano das instituições é, ao mesmo tempo, constituído por elementos característicos de uma cultura patrimonialista, ainda tão presentes nos dias atuais, por princípios tradicionais da administração pública burocrática, e por valores inovadores da administração pública gerencial; portanto, é discutível a existência de modelos puros de gestão.

Muito se fala, atualmente, em modelos de organização mais abertos, flexíveis, que estimulem a participação. Aparentemente, as organizações de produção buscam substituir 
a relação de confronto entre capital e trabalho por meio da criação de espaços de discussão e de colaboração. É comum referir-se, tanto ao taylorismo/fordismo como à administração burocrática, como algo do passado, obsoleto, não mais utilizado. Heloani afirma que não há uma completa ruptura com os princípios de modelos anteriores, e alerta para o fato de que "a hierarquia, a fiscalização e o controle do trabalho - tão caros a esses sistemas -, estão se travestindo, adornando-se com uma nova roupagem, mais adequada aos tempos do 'politicamente correto'" (2003, p.126). Corroborando a tese da inexistência de modelos puros, Paula argumenta que o modelo de administração pública gerencial é "participativo no nível do discurso, mas centralizador no que se refere ao processo decisório, à organização das instituições políticas e à construção de canais de participação popular" (2005b, p.41), e ressalta que, embora esse modelo de gestão "afirme inspirar-se em uma abordagem participativa, há novos mecanismos de controle dos funcionários e a participação é bastante 'administrada' " (2005b, p.43).

Nessa mesma perspectiva, Merlo, Zanini, Furstenau e Pacini mostram que as inovações na administração pública geraram um modelo de gestão híbrida, que compreende elementos do fordismo, do taylorismo e do toyotismo. Entretanto, "esse 'frankstein' gerencial não oferece contrapartida alguma, de nenhum dos modelos, nem o salário fordista, nem a possibilidade taylorista de crescer na carreira, tampouco a valorização e a autonomia toyotistas" (2004, p.374).

Constata-se, dessa forma, que, apesar do recorrente discurso gerencialista, as organizações públicas estão inseridas em um contexto cercado de limitações que reúne restrições orçamentárias, inexistência de condições adequadas para o desenvolvimento do trabalho, recursos materiais e humanos insuficientes, peso da estrutura burocrática, impossibilidade de ascensão profissional (mudança de cargo), baixo poder aquisitivo do servidor, somadas a uma atitude hostil da sociedade dirigida a tudo o que tem origem no Estado, que prega a valorização do privado em detrimento do público. Fala-se dos serviços ruins das escolas, dos hospitais, dos museus, dos órgãos públicos de maneira geral, em uma tentativa constante de desqualificação dos mesmos. Verificase, na prática, uma verdadeira campanha caracterizada por atitudes de desprezo, discriminação, descrédito e desvalorização direcionada a esse setor. Por público, considera-se tudo o que é ineficiente, associado ao desperdício, à corrupção, à falta de controle e coordenação, e o privado é apontado como o lugar de eficiência e de excelentes resultados. O serviço público carrega consigo características depreciativas atribuídas tanto aos órgãos em si quanto aos servidores que neles trabalham.

Vale lembrar que não é de hoje que essa categoria de servidores é representada por uma imagem pejorativa. No início da década de 50, Armando Cavalcanti e Klecios Caldas compuseram Maria Candelária, marchinha carnavalesca que fez muito sucesso na época, e transformaram o nome da música em um dos mais conhecidos estereótipos do funcionário público. A letra fala, de forma irônica, de uma funcionária pública padrão, que faz tudo, menos trabalhar. Há, também, uma conhecida e antiga piada que conta a história de um leão que fugiu do zoológico e come vários funcionários públicos sem chamar a atenção de ninguém; somente quando o animal comete um erro, comendo o moço que serve o cafezinho, ele é encontrado e capturado. Uma imagem estereotipada bastante usada é a do paletó esquecido sobre a cadeira, que só é resgatado no final do expediente, quando o servidor 
Busca-se pessoas avessas a perspectivas de longo prazo, às trajetórias de carreira gravadas na pedra e a qualquer tipo de estabilidade (Bauman, 2008). malandro, avesso ao trabalho, retorna para assinar o ponto.

Realmente, fala-se mal do servidor público há muito tempo, entretanto, a partir de 1995, com a reforma do Estado implementada pelo governo $\mathrm{FHC}$, os ataques e as críticas se intensificaram. Estes passaram a ser responsabilizados por todas as mazelas associadas ao governo.

Cabe ressaltar que não se ignora a corresponsabilidade de parte dos servidores públicos no agravamento da imagem negativa dessa categoria. Infelizmente, existem servidores desengajados e descompromissados que em muito contribuem para a intensificação da própria discriminação. Não há dúvida de que os maus trabalhadores terminam por funcionar como excelentes trunfos para os defensores da diminuição do número de servidores públicos, favorecendo, desse modo, a propagação da ideia de que a única saída é o enxugamento da máquina estatal. Privatização e terceirização surgem, então, como alternativas indiscutíveis para a solução da ineficiência do setor público.

Faz-se imenso, portanto, o esforço para lutar contra o estereótipo pejorativo do funcionário acomodado, sem ambição intelectual, despreocupado com resultados, e especialmente, privilegiado por ganhar muito e trabalhar pouco. Identifica-se, assim, um novo cenário que gera significativos impactos na produção de subjetividade da categoria em questão e que impõe grandes desafios para o enfrentamento das adversidades presentes no cotidiano do servidor público.

\section{O servidor público frente às exigências do mundo do trabalho}

Nesse novo (velho) mundo do trabalho no qual o servidor público está inserido, procurase trabalhadores generalistas, flexíveis, atualizados, criativos, abertos a mudanças, de fácil adaptabilidade, prontos a assumir as mais diferentes tarefas (do tipo pau-pra-todaobra), preparados para abandonar as próprias inclinações e abraçar novas prioridades. A preferência entre os empregadores está nos trabalhadores flutuantes, sem vínculos, compromissos ou ligações emocionais anteriores, disponíveis para atenderem a todo chamado de emergência, assumirem atribuições extras ou serem realocados a qualquer momento. Busca-se pessoas avessas a perspectivas de longo prazo, às trajetórias de carreira gravadas na pedra e a qualquer tipo de estabilidade (Bauman, 2008).

Partindo desse padrão desejável de trabalhador, tão em voga nos dias de hoje, cabe analisar se as organizações públicas propiciam condições para o servidor desenvolver o perfil ideal de trabalhador traçado pela maioria dos empregadores. Em que medida os servidores públicos conseguem ser reconhecidos e valorizados frente às exigências de um mundo do trabalho embebido na lógica do trabalhador autônomo e empreendedor? Ainda há espaço no mundo trabalho do século XXI para essa categoria?

Para tal análise, destacamos alguns elementos que configuram o cotidiano do servidor público, buscando fazer um confronto entre as diferentes características do trabalho nas organizações públicas e nas empresas privadas, dando ênfase aos binômios: estabilidade/ instabilidade; rotina burocrática / flexibilidade e carreira linear/ vínculos frouxos.

\section{a) Estabilidade $X$ instabilidade}

Em um mundo do trabalho imerso em constantes transformações, a instabilidade, a 
transitoriedade e a descontinuidade assumem ares de lugar comum. Já "a percepção fordista do tempo", bem representada pelo planejamento a longo prazo e pelos vínculos duradouros, adquire feições de algo ultrapassado, obsoleto, não mais adequado à lógica da acumulação flexível que atravessa as novas relações de trabalho. Nos tempos áureos do fordismo, a mudança constante de empresa desqualificava o trabalhador; hoje a permanência por um longo período em um mesmo ambiente laboral é interpretada como acomodação. "A palavra de ordem é antes seguir em frente que estabelecer-se" (Sennett, 2006, p. 12).

Todavia, apesar de todo um discurso em prol da flexibilidade e da versatilidade, o trabalho no setor público continua atraente, mesmo que em condições menos favoráveis geradas pela perda de alguns direitos e benefícios. Identifica-se, ainda, um significativo número de trabalhadores empenhados em vencer a disputada corrida por um emprego seguro no serviço público.

Segundo reportagem publicada na revista Isto É, em fevereiro de 2010, sob o título Concurso: o sonho da estabilidade, uma vaga no serviço público transformou-se em objeto de cobiça dos melhores cérebros do País. A estimativa é que mais de dez milhões de brasileiros estejam preparandose para prestar concurso, visando a ocupar uma das 80 mil vagas que foram abertas nas repartições federais, estaduais e municipais.

A esperança de um emprego estável alimenta uma cadeia milionária de negócios. Livros e apostilas direcionados para a preparação de concursos já representam o segmento que mais cresce no mercado editorial. Outra confirmação da expansão do mercado é o aumento do número de empresas e fundações que aplicam as provas. A ANPAC (Associação Nacional de Proteção e Apoio aos Concursos) afirma que o número saltou de 20 para mais de 100 nos últimos cinco anos (Do Rio, 2010).

Crescem, também, de modo surpreendente, os cursinhos preparatórios, antes pequenos empreendimentos, hoje excelente ramo para investimento. A Gran Cursos, localizada na Capital Federal, evidencia bem a expansão desse ramo. Intitulando-se uma escola para concursos públicos, conta hoje com mais de 20 mil alunos, que pagam mensalidade média de mil reais. Seu faturamento anual é superior a 200 milhões (Aquino, Nicácio, \& Guedes, 2010).

Um vínculo empregatício estável constitui um dos maiores atrativos para o ingresso e a permanência no serviço público. A figura de um trabalhador que abre mão de projetos profissionais associados à vocação e aos sonhos em troca de um porto seguro, mesmo que seja fora da sua área de formação e interesse, é cada vez mais frequente.

Sabe-se que as vagas na iniciativa privada não atendem à demanda crescente da classe trabalhadora. Além de serem em número reduzido, apresentam um alto grau de exigência, geralmente desproporcional aos benefícios oferecidos pelo contratante. Um grande número de trabalhadores, diante dos constantes impedimentos, incertezas e turbulências de um mundo do trabalho globalizado, almeja uma atividade laboral estável, segura, que garanta uma renda certa no final de cada mês, donde a procura por um emprego público.

\footnotetext{
Nenhuma empresa, de qualquer porte ou setor, promete mais aos empregados mantê-los por toda a vida produtiva, como nas gerações passadas. E, claro, nas grandes empresas, as vagas são ultradisputadas. Não há lugar para todos. A frustração que resulta dessa aritmética ajuda a levar ao sonho do emprego público (Neves, 2007, p.75)
} 
Surge, nesse cenário de instabilidade das relações de trabalho, a categoria dos concurseiros, que pode ser dividida em dois grupos: o primeiro, dos candidatos a concurso público que precisam continuar trabalhando para o seu sustento, mas que dedicam parte relevante do seu tempo à preparação para os concursos, e o segundo grupo, o dos concurseiros profissionais, que se dedicam exclusivamente aos estudos, não possuem atividade remunerada e se mantêm com a ajuda familiar ou com algumas reservas econômicas obtidas em empregos anteriores. Tanto o candidato que estuda e trabalha como o concurseiro profissional, para o alcance das suas metas, não raramente abdicam de momentos de lazer e de descanso como também do convívio familiar. Ambos enfrentam uma rotina extremamente cansativa e penosa, isso sem considerar que boa parte se debruça sobre conteúdos programáticos distantes dos seus interesses, vocações e formação profissional, o que torna mais difícil essa empreitada.

Albrecht, a partir de um estudo intitulado Sentido do trabalho para concurseiros: a busca do emprego estável como estratégia de inserção no mundo do trabalho contemporâneo, sinaliza que a opção por concursos públicos é proveniente da frustração com a inserção profissional no setor privado, e que "os concurseiros exprimem a situação econômica, social e educacional vigente e os obstáculos no mundo do trabalho; vêem no serviço público garantia de um emprego estável" (2010, p. 10). Na busca incessante por segurança e na tentativa de maximizar seus investimentos nos estudos preparatórios, rompem com a profissão que escolheram ou com o trabalho que desenvolviam. Candidatam-se ora para cargos de nível médio, ora para cargos de nível superior, para funções compatíveis ou não com a sua área de formação - a garantia de inserção no mundo do trabalho é que prepondera.
Uma outra pesquisa realizada por Silva (2004) - que teve como objetivo analisar o significado do trabalho para jovens portadores de diploma de graduação em um momento em que se vivencia uma intensa precarização e altos índices de desemprego - constatou que a expectativa de ingresso no serviço público não era uma opção, e sim, uma saída para enfrentar as dificuldades geradas pela instabilidade no mercado de trabalho.

Vale investigar, contudo, como se sente o servidor público depois de ganhar uma corrida que teve como principal objetivo um emprego estável, sobretudo se o prêmio que ele conquistou não é de um alto cargo com excelentes salários e benefícios, geralmente restritos a poucas oportunidades no setor Judiciário e Legislativo, como ele lida com um prêmio que garante a segurança financeira, porém que vem acompanhado de um olhar preconceituoso de parte da sociedade, na qual os gurus da administração vendem a ideia de que o trabalhador ideal é o empreendedor, alguém avesso a vínculos estáveis, que não se acomoda, ou mais exatamente, não se fixa por muito tempo em um mesmo lugar.

\section{b) Rotina burocrática X flexibilidade}

A flexibilidade tornou-se um imperativo organizacional frente ao mercado altamente competitivo de um mundo globalizado. A sobrevivência das empresas depende da elasticidade institucional. Celeridade, adaptação e leveza são valorizadas socialmente, em contraposição à rotina burocrática das hierarquias piramidais weberianas, símbolo dos tempos áureos do fordismo, que precisa ser banida dos setores dinâmicos da economia.

Empresas perfeitamente viáveis são estripadas ou abandonadas, empregados capazes ficam a deriva, em vez de serem recompensados, simplesmente porque a 
organização deve provar ao mercado que pode mudar (Sennett, 1999, p.59)

A conformação dura, pesada e estável associou-se a um padrão obsoleto e antiquado, e comparece como sinal de fraqueza, indicando ao mercado que a empresa não é capaz de inovar, de gerir processos de mudanças e de atender às exigências voláteis da sociedade (Sennett, 2006).

A força de trabalho central das empresas é reduzida, e parte das atribuições é transferida para os terceirizados, temporários e subcontratados. Volume e tamanho deixam de ser recursos para se tornar riscos. A administração de uma equipe grande torna-se onerosa. No capitalismo, leves engajamentos e vínculos empregatícios duradouros não são recomendados. $\mathrm{Na}$ obsessão pela dieta de emagrecimento, os empresários elegem como principal estratagema da arte de administrar a redução de excessos, de gorduras, o que propicia leveza para o capital, permitindo que ele se mova mais rapidamente e que torne a amplitude de sua viagem cada vez mais global (Bauman, 2001).

Atacam-se as formas rígidas de burocracia... Pede-se aos trabalhadores que sejam ágeis, estejam abertos a mudanças a curto prazo, assumam riscos continuadamente, dependam cada vez menos de leis e procedimentos formais (Sennett, 1999, p. 9)

E quanto ao servidor público, como avaliar o seu dia a dia nesse contexto? As organizações estatais constituídas por modelos predominantemente burocráticos propiciariam espaços para práticas laborais flexíveis? Quais são as possibilidades de criação e de inovação de um trabalhador em um órgão público diante das amarras da legislação que não raramente subtrai-Ihe a autonomia? Como equilibrar administração flexível e manutenção dos princípios básicos do Estado de Direito como: legalidade, impessoalidade, regras formais e universais sem o contrapeso das normas e dos regulamentos? Os órgãos públicos e seus servidores estariam condenados à extinção frente a essa lógica mercadológica que impõe como condição para a sobrevivência a mudança constante?

\section{c) Carreira linear $X$ vínculos frouxos}

A regularidade de uma carreira linear construída em uma única empresa, a especialização em uma atividade determinada, a possibilidade de planejamento a longo prazo e a segurança em relação ao futuro - características presentes principalmente nos países mais avançados onde o Estado de bem-estar social revelou uma estrutura sólida - são diretamente afetadas pelo processo de reestruturação produtiva.

No capitalismo flexível, a estrada reta da carreira tradicional é bloqueada; surgem no percurso desvios, múltiplas direções. A carreira "que avança passo a passo pelos corredores de uma ou duas instituições, está fenecendo, e também a utilização de um único conjunto de qualificações no decorrer de uma vida de trabalho" (Sennett, 1999, pp. 20-21). A concepção da constituição de carreiras lineares associada a degraus/ subida/verticalidade dá lugar a mobilidades horizontais ou transversais, a pulverização de experiências. O trabalhador precisa ser maleável e reconverter-se permanentemente, enfrentar acontecimentos inesperados, ser capaz de reinventar continuamente a sua atividade laboral, buscando sempre novas especialidades. Para manutenção da sua empregabilidade, torna-se estratégico, de tempos em tempos, mudar de empresa, como meio de adquirir novas competências. 
Contratantes e contratados mantêm laços frouxos: "a organização incha e se contrai, empregados são atraídos ou descartados à medida que a empresa transita de uma tarefa a outra" (Sennett, 2006, p. 50). O setor de trabalho temporário está em franca expansão; hoje o maior empregador dos Estados Unidos já não se chama General Motors ou IBM - é a empresa Manpower, fornecedora de mão de obra temporária. Essa empresa disponibiliza para o mercado americano um gigantesco exército de reserva nas mais diversas especialidades, que pode trabalhar por vezes em dois ou três lugares no mesmo dia.

Essas transformações implicam, na verdade, significativas mudanças na morfologia da atividade laboral, sinalizadoras de um processo de metamorfose, e não de desaparição e de perecimento da mesma, como defendem algumas correntes eurocêntricas. A classeque-vive-do-trabalho (Antunes, 1999) hoje em dia apresenta uma conformação mais complexa, heterogênea e fragmentada, diversa da que predominou nos anos de apogeu do taylorismo/fordismo. Essa classe revela um caráter polissêmico e multifacetado, composta, de um lado, por uma minoria de trabalhadores qualificados, polivalentes e multifuncionais, com maior possibilidade de exercitar a sua dimensão "intelectual" e experimentar "maior realização no espaço de trabalho"; de outro lado, compóe-se de um enorme incremento do subproletariado constituído por trabalhadores terceirizados, subcontratados, temporários, entre tantas outras formas assemelhadas de informalidade e de precarização do trabalho disseminadas em todas as partes do mundo (Antunes, 2005).

Nesse cenário, Chanlat (1996) alerta que pensar em carreira tornou-se paradoxal, porque a ideia de gestão de carreira supõe estabilidade no emprego, remuneração adequada, futuro profissional relativamente planejado e previsível e formação apropriada e ética no trabalho. Para ele, reunir, na atualidade, todos esses elementos é cada vez mais difícil.

Surge, dessa forma, um novo perfil de trabalhador, não mais um executor disciplinado de tarefas prescritas, mas um "trabalhador competente, versátil, que deve vivenciar a flexibilidade e a insegurança das condições de trabalho como um desafio inevitável na sua vida profissional" (Lopes, 2009, p.98).

Busca-se pessoas abertas ao sacrifício e à renúncia, que almejem incessantemente o sucesso profissional, que consigam equilibrar sentimentos de pertencimento e de devoção incondicional a uma empresa com uma postura de indiferença e de naturalidade frente às situações de ruptura de vínculos empregatícios.

Valoriza-se o trabalhador desprendido do passado e voltado para o futuro, que subverte as hierarquias instituídas, revela gosto pelo risco, pela autonomia e vê vantagens em um ambiente incerto e turbulento, um sujeito que não se assusta com o provisório e nem cultiva vínculos duradouros com a empresa, alguém que faça de si mesmo seu melhor patrimônio e empreendimento, que seja seu próprio empresário, assumindo assim a obrigação de gerir a sua vida profissional.

Imerso em uma cultura de rotatividade caracterizada por laços frouxos e relações superficiais e fluidas, o trabalhador deve investir no desenvolvimento de competências transferíveis para o exercício de diferentes atividades profissionais em novos ambientes laborais, mantendo-se, dessa forma, competitivo e empregável diante das turbulências de um mercado globalizado. 
Identifica-se, portanto, a implementação de novos modelos de gestão organizacional voltados para o trabalhador autônomo/ empreendedor, alguém cooptado pela ideologia da excelência, dedicado, com uma sede de desenvolvimento insaciável, trabalhadores receptivos à mudança, à descontinuidade, ao inusitado, e, certamente, enfadados com a rotina, a previsibilidade e a estabilidade, perfil perfeito para os donos do capital - protótipo do trabalhador-padrão do século XXI, feito sobre encomenda para atender à estrutura flexível das empresas contemporâneas.

Nesse contexto, cabe analisar as possibilidades de um servidor público ampliar e diversificar as suas atribuições, adquirindo, assim, novas competências. Quais as chances de esse trabalhador se tornar um empresário de si mesmo? E, especialmente, vale a pena para o servidor público transformar-se em um trabalhador autônomo/ empreendedor? Por fim, resta investigar a quem serve esse padrão ideal de trabalhador, aos ditames do mercado ou às necessidades da classe-que-vive-do-trabalho?

\section{Considerações finais}

Diante do exposto, pode-se inferir que, no mundo do trabalho atual, o servidor público tem um espaço cada vez mais reduzido. É senso comum que essa categoria é constituída por trabalhadores ineficientes e obsoletos. A mídia incansavelmente vende a ideia de um funcionário público privilegiado por trabalhar pouco e ganhar muito, e, acima de tudo, por desfrutar do direito à estabilidade no emprego em tempos de trabalho provisório.

Não é lucrativa para o capitalismo flexível a perpetuação de categorias profissionais como a dos servidores públicos - detentora de direitos trabalhistas, ainda que poucos.

As organizações de trabalho precisam de leveza, de agilidade, de contratos de curta duração para, ao sabor das instabilidades do mercado, contrair-se e expandir-se rapidamente, dispensando ou contratando pessoal (Sennett, 2006).

Nessa perspectiva, o servidor público pode ser identificado como um trabalhador deslocado do contexto, como se estivesse na contramão das demandas dos modelos inovadores de produção, e é discriminado por destoar do ritmo acelerado e frenético das organizações de trabalho calcadas no padrão de acumulação flexível; é, provavelmente, uma categoria em extinção, sem lugar na sociedade contemporânea.

A falta de um espaço de reconhecimento e de valorização interfere no sentido atribuído pelos servidores públicos à sua vida profissional. Torna-se motivo de preocupação o fato, cada vez mais comum, de o trabalho para essa categoria assumir apenas o sentido de porto seguro para o atendimento de suas necessidades financeiras frente à instabilidade do mercado.

Não se pode ignorar que trabalhar é mais do que vender sua força em troca de um salário garantido. Há uma remuneração social embutida nesse processo. A atividade laboral pode ser uma significativa oportunidade de desenvolvimento das potencialidades humanas, atuando como fonte de autorrealização, de autoestima, de experiências psicossociais e de sentido de vida. A recompensa do trabalho não é só a estabilidade financeira; o trabalho comparece também como uma importante fonte de prazer quando existe espaço para o reconhecimento social da contribuição pessoal. A ausência de um julgamento favorável do trabalho limita o estabelecimento de uma dinâmica de reconhecimento e afeta, assim, o processo de ressignificação do sofrimento e da transformação das vivências de desprazer em prazer. 
Essas críticas depreciativas recorrentes atingem diretamente o servidor, pois o reconhecimento está no âmago do prazer e do sofrimento na atividade laboral. Dejours adverte que, entre os trabalhadores,

Há os indolentes e desonestos, mas, em sua maioria, os que trabalham se esforçam por fazer o melhor, pondo nisso muita energia, paixão e investimento pessoal. É justo que essa contribuição seja reconhecida. Quando ela não é, quando passa despercebida em meio à indiferença geral ou é negada pelos outros, isso acarreta um sofrimento que é muito perigoso para a saúde mental (1999, p.34)

Chanlat assinala que, "no decorrer dos últimos vinte anos, os empregados do setor público e notadamente os funcionários sofreram mais ou menos fortemente o discurso sobre sua suposta ineficiência, sua fraca produtividade, até sua verdadeira utilidade" (2002, p.5). Segundo o autor, é comum, na maioria dos países industrializados, ocultarem sua condição de funcionários públicos para não serem ridicularizados nos encontros sociais. Nessa mesma direção, Coutinho, Diogo e Joaquim, ao apresentarem resultados de uma pesquisa realizada com servidores técnicoadministrativos de uma instituição federal de ensino superior, ilustram bem o desconforto vivenciado por alguns servidores na fala de um entrevistado: “'(...com) o pessoal que paga, em determinados casos, eu tenho vergonha de dizer que sou servidor público. Porque o pessoal que paga, com razão, tem que exigir, né...' Há uma discriminação social causada pela má conduta de alguns" (2008, p.4).

Frente a um olhar preconceituoso da sociedade, o servidor experimenta sentimentos ambíguos: por um lado, constrangimento pelo não reconhecimento social do seu trabalho, por outro, orgulho por ser um felizardo, alguém perseverante e capaz que conseguiu conquistar uma vaga no tão disputado e desejado serviço público; saboreia um sentimento de vitória e alívio por deter condições financeiras para o seu sustento e o de sua família, encontrando-se, de certo modo, preservado das incertezas do setor privado.

Por fim, torna-se necessário levantar questionamento quanto à falta de um lugar no mundo do trabalho atual ser um problema exclusivo do servidor público. Constata-se que essa dificuldade se estende também ao setor privado, pois sabe-se que, apesar do discurso corrente que alardeia os benefícios desse setor, tais como maior margem de autonomia, de participação e de realização profissional, na prática, o trabalhador do setor privado está inserido em ambientes bastante competitivos e áridos, e experimenta sentimentos de desproteção e de vulnerabilidade.

Enriquez expõe essa vivência de forma muito clara quando afirma que, perante a lógica do trabalhador autônomo,

os indivíduos estão sempre em situação de prova, em estado de estresse, sentem queimaduras internas, tomam excitantes ou tranquilizantes para dar conta da situação, para ter bom desempenho, para mostrar sua 'excelência' (entramos numa civilização de dopping), e, quando esses indivíduos não são mais úteis, eles são descartados apesar de todos os esforços despendidos (2006, p.6)

A apologia ao trabalhador autônomo/ empreendedor, portanto, revela rachaduras, deixando à mostra que atende em primeiro lugar aos ditames do mercado e não às necessidades da classe-que-vive-do-trabalho. Tanto o servidor público como o empregado do setor privado são afetados pelas frequentes mutações do mundo do trabalho. Ambos vivenciam um intenso movimento de desestabilização e de perda de território nos seus ambientes laborais, o que facilmente pode se converter em um perigoso e preocupante processo de alienação e de sofrimento no trabalho. 


\section{Carla Vaz dos Santos Ribeiro}

Doutora em Psicologia Social pela Universidade do Estado do Rio de Janeiro e professora adjunta da Universidade

Federal do Maranhão, São Luís - MA - Brasil.

E-mail: carlavazribeiro@uol.com.br

\section{Deise Mancebo}

Doutora em História da Educação pela Pontifícia Universidade Católica de São Paulo e professora titular da

Universidade do Estado do Rio de Janeiro, Rio de Janeiro - RJ - Brasil.

E-mail: deise.mancebo@gmail.com

Endereço para envio de correspondência:

Rua Rio Pimenta, 14, Olho d'Água. CEP: 65.067-570. São Luís, MA

Recebido 23/01/2012, Aprovado 29/11/2012.

Referências
Albrecht, P. A. T. (2010). Sentidos do trabalho para concurseiros: a busca do emprego estável como estratégia de inserção no mundo do trabalho contemporâneo. Dissertação de mestrado. Universidade Federal de Santa Catarina, SC.

Antunes, R. (1999). Os sentidos do trabalho. São Paulo: Boitempo Editorial.

Antunes, R. (2005). O caracol e sua concha: ensaios sobre a nova morfologia do trabalho. São Paulo: Boitempo Editorial.

Antunes, R. (2009). Introdução. In I. Mészáros. A crise estrutural do capital (pp. 09-16). São Paulo: Boitempo Editorial.

Aquino, W., Nicácio, A., \& Guedes, F. (2010, 2 de fev.). Concurso: o sonho da estabilidade. Revista Isto É, 2099, 76-82

Azevedo, C. B., \& Loureiro, M. R. (2003, jan./mar.). Carreiras públicas em uma ordem democrática: entre os modelos burocrático e gerencial. Revista do Serviço Público, ENAP, 54(1), 45-61.

Bauman, Z. (2001). Modernidade líquida. Rio de Janeiro: Jorge Zahar Editora.

Bauman, Z. (2008). Vida para consumo: a transformação das pessoas em mercadorias. Rio de Janeiro: Jorge Zahar Editora.

Bressser-Pereira, L (2006). Da administração pública burocrática à gerencial. In L. Bresser-Pereira, \& P. Spink (Orgs.). Reforma do Estado e administração pública gerencial (7a ed., pp. 237270). Rio de Janeiro: Editora FGV.

Chanlat, J.-F. (1996, nov./dez.). Quais carreiras e para qual sociedade? (II). RAE - Revista da Administração de Empresas, 35(6), 67-75.

Chanlat, J.-F. (2002). O gerencialismo e a ética do bem-comum: a questão da motivação para o trabalho nos serviços públicos. In Anais do VII Congreso Internacional del CLAD sobre la Reforma del Estado y de la Administración Pública. Lisboa, Portugal.

Coriat, B. (1994). Pensar pelo avesso: o modelo japonês de trabalho e de organização. Rio de Janeiro: Revan: UFRJ.

Coutinho, M. C., Diogo, M. F., \& Joaquim, E. P. (2008). Sentidos do trabalho e saber tácito: estudo de caso em universidade pública. Revista de Psicologia da Vetor Editora, 9, 99-108.

Dejours, C. (1999). A banalização da injustiça social. Rio de Janeiro: FGV Ed.

Di Pietro, M. S. Z. (2010). Direito administrativo (23a ed.). São Paulo: Atlas.
Do Rio, E. L. (2010, 2 de ago.). Esperança de um emprego estável alimenta cadeia de negócios. Folha de São Paulo, Caderno Poder.

Enriquez, E. (2006, jan./jun.). O homem do século XXI: sujeito autônomo ou indivíduo descartável. RAE - Eletrônica, 5(1), $1-14$.

Harvey, D. (1993). Condição pós-moderna: uma pesquisa sobre as origens da mudança social ( 2a ed.). São Paulo: Edições Loyola.

Heloani, J. R. (2003). Gestão e organização no capitalismo globalizado: história da manipulação psicológica no mundo do trabalho. São Paulo: Atlas.

Lopes, M. C. R. (2009, mar./jun.). Subjetividade e trabalho na sociedade contemporânea. Trabalho, Educação e Saúde, 7, 91-113.

Mancebo, D. (2007). Trabalho docente: subjetividade, sobreimplicação e prazer. Psicologia: Reflexão \& Crítica, 20, 1, 74-80.

Merlo, A. R., C., Zanini, P. A., Furstenau, C. R., \& Pacini, L. (2004). As transformações no serviço público e a saúde dos trabalhadores da seguridade social de Porto Alegre. In A. R. C. Merlo (Org.), Saúde do trabalhador no Rio Grande do Sul: realidade, pesquisa e intervenção (pp. 361- 378). Porto Alegre: Editora da UFRGS.

Neves, R. (2007, 19 de nov.). Apertem os cérebros, o emprego sumiu. Revista Época, 496, 75-76.

Paula, A. P. P. (2005a). Por uma nova gestão pública: limites e potencialidades da experiência contemporânea. Rio de Janeiro: FGV.

Paula, A. P. P. (2005b, jan./mar.). Administração pública brasileira entre o gerencialismo e a gestão social. Revista de Administração de Empresa, 45(1), 36-52.

Sennett, R. (1999). A corrosão do caráter: conseqüências pessoais do trabalho no novo capitalismo. Rio de Janeiro: Ed. Record.

Sennett, R. (2006). A cultura do novo capitalismo. Rio de Janeiro: Record.

Siqueira, M.V., \& Mendes, A. M. (2009, jul./set.). Gestão de pessoas no setor público e a reprodução do discurso do setor privado. Revista do Serviço Público, 60(3), 241- 250.

Silva, M. M. (2004, jul./dez.). O trabalho para os jovens diplomados no novo modelo de acumulação capitalista. Perspectiva, 22(2), 405-424. 